\title{
Reforma agrária, trabalho agrícola e educação rural: desvelando conexões históricas da educação do campo
}

Marlene Ribeiro'

\begin{abstract}
Resumo
0 artigo aborda as conexões históricas da educação do campo que, no seu processo de construção, articula a reforma agrária ao trabalho camponês, sendo esse processo atravessado pelos conflitos entre as forças que representam o trabalho no campo, associado à reforma agrária e à educação, e às forças que representam o capital, vinculado às grandes propriedades rurais e ao agronegócio. Para fortalecer a educação do campo, é importante aprofundar a compreensão desse processo. Para isso, é necessário consultar a história, visando a desvelar os interesses contraditórios vinculados à reforma agrária, associada à relação entre o trabalho agrícola e a educação rural, o que garante ou não a permanência dos agricultores na terra. Com essa finalidade, a análise das conexões entre reforma agrária, trabalho agrícola e educação rural focaliza o período entre 1910 e 1970, abordando as políticas de cooperação norte-americanas estabelecidas com o governo brasileiro, que incluem assistência técnica e educação rural. E, na contramão dessas políticas, aborda ações e iniciativas dos movimentos sociais populares, com destaque para o Movimento de Educação de Base (MEB). Com isso, este estudo poderá contribuir para a compreensão das cercas que se colocam à educação do campo.
\end{abstract}

\section{Palavras-chave}

Educação rural - Trabalho agrícola - Reforma agrária - Educação do campo - História da educação rural. 


\title{
Land reform, agricultural work and rural education: unveiling historical connections
}

Marlene Ribeiro

\begin{abstract}
This article discusses the historical connections of rural education, which articulated land reform and peasant labor in its construction process. Such process has been influenced by the conflict between the forces representing the work in the countryside, associated with land reform and education, and the forces representing the capital, linked to large farms and agribusiness. To strengthen rural education, it is important to deepen the understanding of this process. To this end, it is necessary to refer to history in order to reveal the conflicting interests related to land reform, coupled with the relationship between agricultural work and rural education, which does or does not ensure that farmers remain in the land. For this purpose, the analysis of the connections between land reform, agricultural work and rural education focuses on the period between 1910-1970, and addresses, on the one hand, the cooperation policies the United States established with the Brazilian government, including technical assistance and rural education, and on the other hand, the actions and initiatives of the popular social movements which opposed such policies, especially those of Movimento de Educação de Base (MEB - Grassroots Education Movement). This study may thus contribute to understanding the obstacles faced by rural education.
\end{abstract}

\section{Keywords}

Rural education - Agricultural work - Land reform - Education in the countryside - History of rural education.

I- Universidade Federal do Rio Grande do Sul, Porto Alegre, Rio Grande do Sul, Brasil.

Contact:marlene.ribeiro@ufrgs.br 


\section{Introdução}

Pesquisas sobre educação do campo registram que essa é uma conquista dos movimentos sociais populares que lutam pela terra de trabalho associada à educação, à saúde e, portanto, a uma vida digna para as famílias que vivem e trabalham no campo. Nas várias formas de luta que resultam nessa conquista, as diferentes organizações de trabalhadores e trabalhadoras do campo integradas à unidade do Movimento Camponês (MC) contestam a preparação para o trabalho e a vida urbanos, oferecida com o título de educação rural. Como superação desta, o MC, integrado pela Via Campesina e a Confederação dos Trabalhadores na Agricultura (CONTAG), propõe a educação do campo articulada ao trabalho da e com a terra, trabalho esse que define a vida, produz saberes e projeta uma cultura, conferindo identidade ao camponês (RIBEIR0, 2013).

A educação do campo não se orienta por um modelo acabado, definido de fora, mas constrói-se na luta pela reforma agrária ou pela terra de trabalho, sem a qual é impossível materializar essa educação do campo. Por essa razão, ela é atravessada por interesses antagônicos e, consequentemente, pelos conflitos entre as forças que representam o trabalho no campo - associado à reforma agrária e à educação - e as forças que representam o capital - vinculado às grandes propriedades rurais, ao agronegócio e ao sistema financeiro, que responde pelos seus investimentos e créditos. Seria essa busca da educação do campo associada à terra de trabalho e, portanto, à reforma agrária, um acontecimento novo, próprio do final do século 20 e primeira década do século 21 , ou teria raízes mais profundas a serem buscadas na história?

Tomo essa questão como orientadora da análise, pois me parece importante consultar a história e averiguar se aqueles interesses contraditórios se mantêm e/ou se tomam novos formatos; enfim, se podem ser ou não as bases que dão continuidade aos atuais conflitos entre terra, trabalho, educação no/do campo e capital agrário, industrial, comercial e financeiro. Busco aprofundar essa análise no período que vai dos anos 1910 a 1980, para entender os processos oriundos da relação entre o trabalho agrícola e o capital agrário, que atravessam a educação rural. Com isso, tem-se elementos para compreender os interesses contraditórios que atravessam a educação do campo como superação da educação rural, mantendo, no entanto, seu vínculo com a terra de trabalho e associando a luta pela reforma agrária à construção de um projeto popular de sociedade.

Assim, a reflexão aqui proposta se insere nos estudos que venho desenvolvendo a partir da hipótese de que a relação entre o trabalho agrícola e a educação escolar oferecida aos agricultores reproduz-se, ainda hoje, com enorme intensidade, embora sejam escassos os estudos sobre a formação humana que focalizem especificamente essa relação. 0 preconceito com relação ao mundo camponês - trabalhos, culturas, modos de vida próprios - contagia a percepção de sua educação, identificada como rural. Isso explica por que a relação entre trabalho agrícola e educação rural não tem despertado maiores interesses como tema de pesquisa, bem como por que são poucos os estudos sobre educação rural nas obras de história da educação (CARDOSO; JACOMELI, 2010). Diferente dessa educação rural, a educação do campo, conquistada pelos movimentos sociais populares que dão concretude ao MC, tem atraído uma atenção maior por parte dos pesquisadores, gerando uma rica produção no interior das universidades e organizações de pesquisa, além de cursos de graduação e pós-graduação direcionados à educação do campo.

\section{O capital sob a aparência de políticas de cooperação atinge a educação rural}

Nesta parte do artigo, vou situar a relação entre a terra, o trabalho agrícola e a educação rural na história, focalizando o movimento 
no qual sobressai o controle do capital, implícito nas políticas desenvolvidas nessa área, que assumem a aparência de cooperação por parte dos Estados Unidos da América (EUA). Inicio pelos processos revolucionários ocorridos no México, em 1910, e na Rússia, em 1917, em ambos os casos distribuindo terras aos camponeses, que chegam ao conhecimento, nos países latino-americanos, tanto dos movimentos sociais populares quanto dos setores representativos do capital ${ }^{1}$. Impondo-se sobre os países da América Latina, os EUA lideram o processo de reação para conter o avanço dos movimentos revolucionários identificados como comunistas. Apesar do contexto de repressão a esses movimentos, da crise estrutural do capital iniciada em 1929, e das políticas adotadas no período pós-guerra, identificadas em seu conjunto como Guerra Fria, avançam as organizações dos trabalhadores chineses e cubanos, ocorrendo a Revolução Comunista na China, em 1949, e em Cuba, em 1959 (MORISSAWA, 2001).

Esses acontecimentos vão estimular a constituição de organizações dos trabalhadores urbanos e rurais, mas também vão gerar fortes reações, principalmente da parte dos Estados Unidos, quanto às suas relações com os países da América Latina, resultando na formulação de políticas que lhes permitam obter, ao mesmo tempo, uma preparação dos agricultores para a implementação do seu modelo produtivo agrícola e um rigoroso controle sobre as organizações camponesas (MENDONÇA, 2010). Nessas políticas orientadas por um modelo de desenvolvimento gerador de uma interdependência entre elementos internos e externos, é possível observar um vínculo muito estreito entre os processos relacionados à industrialização, à implantação de um modelo agrícola com base na utilização de máquinas e insumos importados, à reforma agrária em moldes capitalistas e à educação rural. E,

1- Sob a liderança de Emiliano Zapata, os mexicanos buscaram recuperar terras que Ihes foram arrancadas durante o período colonial, enquanto na Rússia, um país atrasado industrialmente, sob o comando de Lenin, foi feita a revolução que deu o poder ao proletariado (MORISSAWA, 2001, p. 32-34). tratando-se do período de 1955-1960, pode-se concordar com Marini (2000, p. 23) no que diz respeito à estrutura agrária que "entra em conflito perigoso com as necessidades sociais e materiais da população brasileira”, porque baseada na "absurda e antieconômica distribuição de terras”. No caso da educação associada a um modelo de desenvolvimento implementado de fora, considerando o Brasil como um país atrasado, Cunha (1980, p. 16) a reconhece "como uma variável política, estratégica, capaz de intensificar o crescimento da renda, produzir a modernização ou construir uma sociedade justa”, o que não deixa de suscitar dúvidas. Assim, as políticas adotadas tanto visam à fixação dos agricultores na terra para não aumentar os conflitos por parte da população trabalhadora sem emprego nas áreas urbanas, quanto à imposição de um modelo de desenvolvimento rural com base no uso de máquinas e técnicas agrícolas, junto com a aplicação de insumos indicados pelos técnicos norte-americanos, responsáveis pelos programas decorrentes dos acordos bilaterais entre Brasil e Estados Unidos (CALAZANS, 1981; 1993).

Ainda sobre a questão do desenvolvimento, João Bosco Pinto (1981) começa por defıni-lo como econômico-social, relacionando-o à produção, distribuição e consumo de bens, articulado às relações sociais materializadas nesse processo que assume uma dimensão histórica. Passa, em seguida, a abordar o desenvolvimento nos países da América Latina, apontando a necessidade da reforma agrária, mais evidente a partir dos anos de 1930, quando se intensifica a industrialização. Nesse sentido, e para o modo capitalista de produção vigente nesses países, a existência do latifúndio nem estimulava a penetração do capital no campo, sob a forma de investimentos em maquinarias e uso de tecnologias de produção, nem contribuía para a proletarização dos camponeses. É nesse contexto, em que se coloca a modernização da sociedade brasileira associada ao desenvolvimento do capitalismo 
no campo, que emerge a questão da reforma agrária, até porque processos revolucionários no México, Bolívia e Cuba já a haviam promovido nesses países. E, além destes, também foi feita a reforma agrária no Japão, na Coréia e no Egito, conforme registra Veiga (1994). Por isso, concordando com Pinto (1981), é duvidoso esperar que aconteça o desenvolvimento do capitalismo no campo brasileiro para, com isso, melhorar os padrões de vida das populações rurais, o que só poderá ocorrer, de fato, com a organização e luta desses trabalhadores, cujo desafio maior a ser enfrentado é a concentração da propriedade da terra, uma herança colonial que se mantém e aprofunda em nossos dias (PRADO JÚNIOR, 2005).

Nessa perspectiva, a preocupação com a escola para as populações rurais manifesta-se, inicialmente, nos anos de 1910, quando a intensificação dos processos produtivos fabris vai atrair muitas famílias de trabalhadores rurais para as áreas urbanas, desafiando o Estado brasileiro para a questão social e, mais propriamente, para o seu controle. Mas são principalmente as greves operárias, iniciadas em 1906 e intensificadas em 1917, e as lutas contra a alta do custo de vida que irão colocar em evidência o inchamento das cidades e o descompasso entre os empregos existentes nas áreas industriais, comerciais e de serviço, e a demanda da mão de obra imigrante e desempregada.

Em relatório ${ }^{2}$ coordenado por Calazans (1979), pesquisadores da Fundação Getúlio Vargas (FGV) buscam na história o momento em que ocorre a aceleração dos processos de industrialização no Brasil, associados ao surgimento de centros urbanos de médio e grande porte, decorrentes da emigração de populações rurais. Até os anos de 1940, dois terços da população brasileira ainda se concentrava nas áreas rurais, o que começa

2- Este documento analisa os resultados de um convênio entre 0 Instituto de Estudos Avançados em Educação (IESAE) da Fundação Getúlio Vargas (FGV) e o Instituto Nacional de Estudos Pedagógicos (INEP), como contribuição à formulação de políticas de educação rural, buscando reconstituir a memória das iniciativas dos poderes públicos voltadas às populações rurais (CALAZANS et al., 1979). a mudar com as emigrações das populações que aí viviam e que se deslocam em busca de trabalho e de melhoria dos seus padrões de vida, o que pode ser confirmado pelos índices de alfabetização e de consumo superiores nas áreas urbanas em relação às rurais: "Essas populações urbanas já contavam com maiores facilidades escolares, com algumas medidas protetoras da legislação social e trabalhista e do amparo à saúde" (CALAZANS et al., 1979, p. 1). As populações rurais, pelo contrário, não contavam com as condições necessárias à implementação da educação escolar, sendo, em sua maioria, constituídas de pessoas analfabetas com baixo nível de renda, que estavam sujeitas às doenças endêmicas por serem subalimentadas e, ainda, por não contarem com apoio de políticas de saúde e educação. 0 documento acima referido (CALAZANS et al., 1979) registra uma série de problemas que atingiam as populações rurais, refletindo-se sobre a produção agrícola. Entre esses problemas, destacam-se a precariedade dos meios de transporte e a dificuldade de identificar mercados para as pequenas safras obtidas com grandes sacrifícios, que apontavam para uma solução coletiva através da criação de cooperativas, tal como já vinha ocorrendo em outras regiões e/ou países. É nessa época que, no Brasil, os interesses se deslocam de um movimento reduzido à alfabetização para uma ampliação da oferta da educação rural, defendida em 1933 por Getúlio Vargas, o qual, com a chamada Revolução de 30, torna-se presidente da República.

A ampliação da oferta de educação rural seria feita através de uma campanha que, para além da instrução, oportunizasse aos agricultores as condições de ter consciência dos seus direitos, de fortalecer seu espírito e também seu corpo através da higiene e do trabalho (MOTA, 2010). Nesse contexto de estímulo à educação rural, fundam-se entidades direcionadas ao seu desenvolvimento e oferta: "Difundem-se as ideias do ruralismo pedagógico mexicano e a metodologia de suas missões rurais; organizam-se cursos de capacitação do 
magistério rural" (PAIVA, 1983, p. 128). Com isso, educadores e administradores reúnem-se para pensar formas de implantação das escolas fixas nas áreas rurais, bem como analisar a viabilidade de escolas ambulantes atenderem populações em áreas de difícil acesso, ampliando a oferta de escolas rurais.

É na década de 30 do século 20, portanto, com o movimento que levou Getúlio Vargas ao poder, que as discussões acerca da educação rural são retomadas com maior vigor, uma vez que a mudança no quadro político do país inclui a educação como um dos seus compromissos. Observa-se, então, uma política voltada à educação das populações campesinas, caracterizada como ruralismo pedagógico, com o objetivo de fixar os trabalhadores rurais nas suas regiões de origem para evitar o aumento da população nas áreas urbanas das grandes cidades, em decorrência dos que imigram em busca dos empregos nas indústrias nascentes (PAIVA, 1983; MOTA, 2010). Porém, a proposta de ruralização do ensino é mais uma ideologia do que propriamente um projeto de intervenção com resultados práticos (NAGLE, 2001). Mas, para evitar a emigração, seria necessário que as políticas para a educação rural fossem acompanhadas da promoção de condições de trabalho e de uma vida digna para os agricultores, o que, de fato, não ocorreu (LIRA; MELO, 2010).

0 fracasso da educação rural era comprovado pela existência de um grande número de analfabetos, o que justificava as propostas dos defensores do ruralismo pedagógico. Para eles, a escola deveria estar associada à produção agrícola e adaptada às necessidades das populações rurais, de modo a formar os filhos dos agricultores para permanecerem na terra (CALAZANS, 1993). Porém, como aponta Nagle (2001), elas não passavam de um discurso com boas intenções. 0 ruralismo influenciou apenas parcialmente a legislação e as práticas escolares, e, na expressão de seus defensores, sempre se fazia acompanhar das orientações nacionalistas que promoviam a exaltação da terra e do povo brasileiro que nela vivia: "Nesse sentido, 'terra' se traduzia como 'produtos da terra' e, por meio disso, 'terra' e 'agricultura' tornaram-se sinônimos”. Dessa forma, a escola desempenhou um papel importante na formulação e difusão da ideologia do "Brasil-país-essencialmenteagrícola", contribuindo, de certo modo, para fixar os trabalhadores rurais na terra (NAGLE, 2001, p. 303).

Visando a expandir o ensino e difundir a arte e o folclore nas zonas rurais, foi fundada a Sociedade Brasileira de Educação Rural (SBER), em 1937, ano em que Getúlio impôs-se no poder, criando o chamado Estado Novo. E, de acordo com Prado (1995, p. 5), o “estudo do pensamento educacional no Estado Novo (19371945) encontra preciosas fontes nas ideias do ruralismo pedagógico". Nesse contexto, e para além de conter o movimento emigratório do campo para a cidade, a alfabetização assume um caráter ideológico associado à pregação moral e cívica e aos princípios da disciplina. São oferecidos cursos normais rurais de preparação para o magistério nas escolas rurais, bem como são organizadas "missões rurais"3 de cunho assistencialista. (BARREIRO, 2010, p. 50; CALAZANS, 1981, p. 35-40). Porém, o que define o movimento ruralista é a questão político-ideológica oculta pelo discurso sobre a educação: "Comprometido com a manutenção do 'status quo', contribui para uma percepção enviesada da contradição cidade-campo como algo 'natural' concorrendo, consequentemente, para a sua perpetuação" (MAIA, 1982, p. 28).

As políticas adotadas por Vargas, nas quais se insere a educação rural, não estão nem um pouco dissociadas dos interesses norte-americanos pelo que ocorre na América Latina e, em especial, no Brasil. Dando continuidade a essa política, foi criado, em 1942, o Institute of Inter-American

3- As Missões Rurais de Educação deram suporte às ações da CNER e eram desenvolvidas nos centros sociais da comunidade. A CNER estava organizada em quatro setores: Estudos e Pesquisas, Treinamento, Missões Rurais e Divulgação. Ao setor Missões Rurais, cabia assistir e supervisionar as atividades desenvolvidas nas missões rurais, além de admitir técnicos formados em seus cursos (BARREIR0, 2010, p. 50). 
Affairs (IIAA), no período em que ocorria a II Guerra Mundial e, no Brasil, Getúlio Vargas mantinha-se no poder. Esse instituto foi o que organizou o primeiro Programa de Assistência Técnica, propondo acordos com objetivo de aperfeiçoar as condições de saúde, educação e agricultura na América Latina e inaugurando, dessa forma, uma influência permanente dos Estados Unidos na área da educação oferecida às populações rurais. Como resultado desse programa e visando a consolidar os propósitos da política norte-americana, foi criada a Agência de Serviço de Cooperação para gerir os recursos aplicados na região. Detendo a confiança do governo norte-americano, os técnicos do Serviço de Cooperação procuravam aplicar suas práticas pedagógicas junto aos agricultores, buscando romper as resistências destes, de modo que estes aceitassem e aplicassem as inovações relacionadas aos projetos que desenvolviam, com aporte financeiro dos países latino-americanos onde estavam atuando. Com isso, confirma-se a análise de Tragtenberg (2004) sobre a política norte-americana adotada para submeter, dominar e controlar os países identificados como subdesenvolvidos da Ásia, África e América Latina.

Sob a coordenação e financiamento do Ministério da Agricultura (MA), ainda durante o governo de Getúlio Vargas, foram criadas colônias agrícolas e foi estimulada a organização de núcleos coloniais, como órgãos de fomento ao cooperativismo e ao crédito agrícola. Essas iniciativas propunham-se a forjar uma nova cultura, incentivando a formação de hábitos de higiene associados à vida sadia e ao aprendizado de novas técnicas agrícolas, bem como a ofertar cursos de aprendizado agrícola com padrões equivalentes aos do ensino elementar, regulamentado em 1934, com o objetivo de formar capatazes rurais. Nesses mesmos padrões, foi criado um curso de adaptação para oferecer a capacitação profissional dos agricultores (CALAZANS, 1993, p. 20).

Os interesses por parte de instituições públicas e privadas norte-americanas intensificam-se nos anos 1940, a partir da concepção de Terceiro Mundo, disseminada entre os países latino-americanos, com destaque para a Inter-American Affairs Association (IAA), de Nelson Rockefeller (MENDONÇA, 2007). Nessa mesma década, foram desenvolvidos programas de educação rural pelo Ministério de Educação e Cultura (MEC) ou pelo Ministério da Agricultura e alguns em parceria. Calazans (1993, nota 18, p. 21) destaca a criação da Comissão BrasileiroAmericana de Educação das Populações Rurais (CBAR), resultante de um acordo efetuado em 1945 entre os governos do Brasil, através do Ministério da Agricultura, e dos EUA, através daquele instituto de Nelson Rockefeller, que, posteriormente, foi substituído pelo Education Division do institute for Inter-American Affairs (IAA), que representava a Divisão de Educação desse instituto para os Assuntos Interamericanos (CALAZANS, 1981, p. 5). Sob a responsabilidade da CBAR, foram implantados os Centros de Treinamento para os trabalhadores rurais adultos e os Clubes Agrícolas para crianças e jovens. Com isso, criaram-se as condições para a formação de técnicos e lideranças, buscando incutir nos trabalhadores o amor à terra e ao trabalho, como se estes - terra e trabalho - lhes fossem estranhos.

Com a CBAR gerenciando os programas de educação rural, essa modalidade de educação recebe um grande estímulo em todas as regiões brasileiras, incluindo entre seus objetivos a aprendizagem de novas técnicas agrícolas. Visava a introduzir um modelo de agricultura associado às ideias de "desenvolvimento" e "progresso", de modo a gestar a dependência dos produtos, insumos e da maquinaria próprios do modelo agrícola norte-americano, difundido como mais avançado. Dentre os programas desenvolvidos pela CBAR, destacam-se os Centros de Treinamento, as Semanas Ruralistas e os Clubes Agrícolas, além do projeto de "aldeia rural”, surgido em 1945, associado a um plano de colonização para as aldeias. Define-se também, segundo Calazans (1993, p. 22), o papel da Campanha Nacional de Educação Rural (CNER) 
e do Serviço Social Rural (SSR): "As duas experiências realizam-se ao longo de um período que se caracteriza, no âmbito mundial, pela Guerra Fria e, na conjuntura nacional, sobretudo pelo período desenvolvimentista do governo Juscelino Kubitschek".

Em cumprimento às deliberações resultantes da Terceira Conferência Interamericana de Agricultura, ocorrida em Caracas, em 1945, o Ministério da Agricultura decidiu elaborar um Plano Quadrienal de Trabalho, incluindo nesse plano a educação rural. Essa contaria com o suporte de um acordo, efetuado em outubro desse mesmo ano, entre esse Ministério e a Fundação Inter-Americana de Educação, para o período de 1946-1948. A concretização do programa de cooperação técnica

[...] deveria ainda incluir o fornecimento, por parte do governo norte-americano, de um grupo de especialistas em Ensino Agrícola; a realização, em cooperação com autoridades brasileiras, de estudos e pesquisas através de viagens de educadores e técnicos nacionais à América do Norte; o treinamento local de professores de ensino técnico agrícola; a aquisição de equipamentos e material de ensino - dentre eles rádio e cinema - nos Estados Unidos, além de Missões Rurais Ambulantes. Em contrapartida, todas as dotações materiais pertencentes à CBAR seriam de propriedade do governo brasileiro. (MENDONÇA, 2007, p. 258).

Até o final dos anos 1940, principalmente após o término da II Guerra Mundial, as relações diplomáticas estabelecidas entre os EUA e os países da América Latina eram bastante favoráveis aos interesses norte-americanos, principalmente na área do comércio e dos investimentos que os mesmos faziam na região. Por esse motivo, os Estados Unidos pretendiam consolidar tais relações, o que demandava promover, no período pós-guerra, uma política que contivesse o avanço do comunismo, ou a "ameaça vermelha" aos "países livres". Nessa linha de interesses, foi criada, em 1948, a Organização dos Estados Americanos (OEA), na Conferência de Bogotá, na Colômbia, com o sentido de estabelecer laços mais concretos entre os EUA e os países latino-americanos. Na verdade, com a criação da OEA, o governo dos Estados Unidos tanto pretendia preservar os interesses do capital investidos naqueles países quanto manter, nos mesmos, o modelo agrícola que os tornava exportadores de produtos primários a baixos preços, bem como usuários de tecnologias e implementos agrícolas importados.

$\mathrm{Na}$ Carta da Organização dos Estados Americanos (OEA), assinada pelos representantes dos Estados presentes na Nona Conferência Internacional Americana, realizada em abril de 1948, em Bogotá, por isso identificada como "Carta de Bogotá", naquilo que foi acordado para o desenvolvimento integral e em sintonia com os propósitos contidos na Aliança para o Progresso, estavam incluídos os campos "econômico, social, educacional, cultural, científico e tecnológico” (PASSOS, 2009). No Brasil, essa carta foi ratificada em 1952 pelo presidente Getúlio Vargas ${ }^{4}$. Levando em conta os interesses que marcavam as iniciativas do governo norte-americano na ocasião, pode-se indagar sobre qual concepção estaria sustentado o desenvolvimento integral proposto, a do individuo a ser preparado para o trabalho sob a forma de emprego, ou a da formação humana que vincula o trabalho produtivo à educação escolar, tal como vem sendo proposto pela educação do campo ${ }^{5}$.

4 - No Brasil, pelo Decreto no 30.544, de 14 de fevereiro de 1952, Getúlio Vargas promulga a Carta da Organização dos Estados Americanos, firmada em Bogotá, a 30 de abril de 1948. "Capítulo VII - Desenvolvimento Integral, Art. 30. Os Estados membros, inspirados nos princípios de solidariedade e cooperação interamericanas, comprometem-se a unir seus esforços no sentido de que impere a justiça social internacional em suas relações e de que seus povos alcancem um desenvolvimento integral, condições indispensáveis para a paz e a segurança. 0 desenvolvimento integral abrange os campos econômico, social, educacional, cultural, científico e tecnológico, nos quais devem ser atingidas as metas que cada país definir para alcançá-lo". Consulta ao site: <www2.camara.leg.br/.../ decreto-30544-14-fevereiro-1952-340000-publi...17/09/2013>.

5- Na educação do campo, "a emancipação humana está alicerçada em uma formação que articula trabalho-educação-cooperação" (RIBEIRO, 
A educação oferecida às populações rurais expressava, até o final dos anos 40 do século 20, um total desconhecimento das questões que se colocavam a essas populações. Essa síntese conclusiva é formulada por Calazans (1993), na análise que faz do documento "Escola para o Brasil Rural”, resultante de um curso promovido em 1949 pelo Instituto Nacional de Estudos Pedagógicos (INEP), em parceria com o MEC. Afirma a mesma autora que a variedade e a complexidade dos temas propostos não correspondiam nem à realidade nem à escassa formação dos professores leigos que participaram do referido curso.

Apesar da Política de Boa Vizinhança, adotada desde os anos de 1930 por Roosevelt, e da criação da OEA em 1948, na Conferência de Bogotá, as organizações operárias e camponesas criticavam vivamente o governo norte-americano, em particular, as políticas de dominação e controle sobre os países da América Latina. Suas críticas eram alimentadas pelas notícias acerca do comunismo russo e pelos movimentos revolucionários latino-americanos, que, em Cuba, tomariam o poder em 1959. Manifestações, tumultos e severas críticas dirigidas à política estadunidense durante "a visita do vice-presidente Richard Nixon (1958), e a tomada do poder pela Revolução Cubana (1959), forçaram os Estados Unidos a reformular sua postura política em relação às demandas da América Latina” (PASSOS, 2009, p. 3).

Em setembro de 1960, o Conselho da Organização dos Estados Americanos (OEA) realiza uma nova reunião em Bogotá, na Colômbia, a qual resulta na "Ata de Bogotá", em que se reafirma a ideia de que o desenvolvimento econômico e o progresso social estão indissoluvelmente ligados e só poderão ser atingidos se as repúblicas latino-americanas preservarem e fortalecerem suas instituições democráticas. Mas as decisões

2013, p. 418, itálico no original), mas essa não é a educação oferecida pela escola rural, em separado do trabalho identificado como emprego, que não está disponível para todos. Sobre educação integral ou omnidimensional, consultar: GRAMSCI, 2001, v. 2. MARX, 1982; MARX; ENGELS, 1983. tomadas pelos EUA a respeito da cooperação financeira estavam a exigir a criação de um banco para financiar os investimentos nos países latino-americanos. Nesse contexto em que se desenvolvem estratégias político-ideológicas para consolidar a Aliança para o Progresso e para reduzir uma possível influência do comunismo cubano, emerge o Banco Interamericano de Desenvolvimento (BID) para financiamento das políticas definidas pela United States Agency for International Development (USAID), entre cujos objetivos constavam os sistemas agrário e fundiário e a educação rural, como bases da filosofia dessa agência norte-americana, o que pode ser observado na carta resultante dessa conferência (PASSOS, 2009).

A Revolução Cubana balançou a postura dominadora dos EUA, mostrando que a sua política externa não era a mais adequada ao momento e impondo a necessidade de mudanças, o que foi feito através de dois processos intercomplementares: no primeiro, tratava-se de promover, dentro de Cuba, um movimento contrarrevolucionário e, no segundo, de efetivar ações que pudessem conter o possível avanço do comunismo em direção aos demais países latino-americanos. Nesse sentido, era preciso forjar uma proposta ultranacionalista para impedir que avançasse um internacionalismo revolucionário. Nesse contexto, o presidente John Kennedy faz o lançamento da Aliança para o Progresso, durante a $1^{\text {a }}$ Conferência de Punta del Este, no Uruguai, em 1961, comprometendo-se a colocar sob o comando dos EUA a administração das demandas e insatisfações provenientes dos países latino-americanos, considerados subdesenvolvidos (PASSOS, 2009; ROCHA, 2005).

Na pesquisa efetuada por Barbosa (2008) para a sua dissertação de mestrado, a Aliança para o Progresso é lançada durante as duas conferências que ocorreram em Punta del Este, no Uruguai, reunindo representantes de países latino-americanos: a primeira em agosto de 1961 e a segunda em janeiro de 1962: 
As Conferências de Punta del Este, realizadas em 1961 e 1962, denunciaram a fragilidade do sistema institucionalizado com a criação do Tratado de Assistência Recíproca (TIAR) e da Organização dos Estados Americanos (OEA) [...]. (BARBOSA, 2008, p. 25).

Além dos interesses econômicos acerca dos investimentos norte-americanos naqueles países, o comunismo vigente em Cuba desde a Revolução de 1959 também explica as duas reuniões, nas quais sobressaem os discursos reformistas e de solidariedade por parte dos EUA:

Em suma: de um lado, a Aliança para o Progresso foi apresentada como bandeira de luta pela erradicação das injustiças econômicas e sociais na América Latina, a alternativa livre, fiel às "tradições ocidentais e cristãs” do continente, afastada do comunismo soviético; de outro, ainda que não explicitamente, procurava reiterar a hegemonia dos EUA sobre a região, subordinando a unidade pan-americana aos interesses norte-americanos, pelo aprofundamento da dependência econômica aos seus investimentos eminentemente privados. (BARBOSA, 2008, p. 19, aspas do original).

Rocha (2005) analisa a "Carta de Punta del Este”, documento da conferência realizada no Uruguai, em 1961, na qual são registrados os objetivos da Aliança para o Progresso, como resultado do compromisso pós-guerra dos EUA com os países latino-americanos. Por outro lado, a carta revela como esses objetivos estavam voltados a interesses favoráveis ao desenvolvimento econômico do país norteamericano. No que se refere à reforma agrária, aquela carta a define como indispensável para evitar a dependência da importação de produtos primários, o que significava aumentar a produção associada ao processo de industrialização. De acordo com a sua análise, as ideias aí contidas, incluindo as que definiam a educação pretendida, inspiravam-se no positivismo, mais especificamente no evolucionismo de Spencer, para o qual o fracasso e/ou sucesso humanos estão ligados ao esforço e à capacidade de cada um. Dos onze objetivos da Aliança focados no que seria o desenvolvimento, destaco alguns que se referem à relação entre a reforma agrária, o trabalho agrícola e a educação rural, que abordo neste artigo. São eles: aumentar a produção agrícola; impulsionar a reforma agrária, substituindo os latifúndios por um regime justo de propriedade; eliminar o analfabetismo entre os adultos do hemisfério e, até 1970, garantir um mínimo de seis anos de instrução primária a toda a criança em idade escolar na América Latina; modernizar os meios, de modo a avançar o ensino secundário, vocacional, técnico e superior (ROCHA, 2005, p. 5).

Portanto, a Aliança para o Progresso, um programa dos EUA desenvolvido entre 1961 e 1970, visava a promover o desenvolvimento econômico mediante a colaboração financeira e técnica em toda a América Latina, a fim de não permitir que outro país aderisse aos ideais comunistas, como ocorrera em Cuba. Com a Aliança para o Progresso, pelo menos no discurso, a política norte-americana se propunha a oferecer assistência técnica e financeira para aquilo que os países estavam entendendo como "desenvolvimento", objetivando, com isso, revolucionar sem ser necessário fazer uma revolução conforme o modelo comunista, difundido pelo Partido Comunista Brasileiro (PCB). E, dentro dessa "revolução" às avessas, na qual a expropriação da terra do camponês e a exploração do trabalho assalariado eram mantidas, incluía-se uma reforma agrária em moldes capitalistas, com a finalidade de modernizar a produção das "sociedades agrárias tradicionais"6.

6- Na coletânea de livros sobre a questão agrária no Brasil organizada por João Pedro Stédile, uma dessas obras traz os programas de reforma agrária produzidos por partidos políticos, igreja, governos e até pela ditadura militar. Inclui o Estatuto da Terra - Lei no 4.504 de 30/11/1964, identificado como a primeira lei de Reforma Agrária no Brasil (STEDILLE, 2005, p. 119-156). 
De acordo com Lincoln Gordon, embaixador dos EUA no Brasil, no período de 1961-1966, a Aliança para o Progresso se sustentava em dois pilares: a democracia e a educação, de modo que não bastaria a aplicação das reformas impostas; era imperioso que os governos nacionais adequassem os programas às suas necessidades. Gordon destacava a educação como um investimento produtivo, chamando a atenção para os baixos níveis dos recursos humanos, além das deficiências, tanto quantitativas quanto qualitativas, das estruturas educacionais brasileiras, principalmente as que eram destinadas à educação rural; "Nenhuma reforma de base poderia fazer mais para acelerar os desejados processos de progresso econômico e social do que a ampliação e modernização dessas estruturas educacionais" (GORDON, 1962, p. 69, apud PASSOS, 2009, p. 8). Observe-se que o embaixador dos EUA também se utiliza do termo "reforma de base", conferindo-lhe, no entanto, um significado que nega o proposto pelo presidente João Goulart, como veremos adiante. Ou seja, para o embaixador, aquelas reformas estavam associadas aos interesses do capital, em particular, o norte-americano. Mas a Conferência de 1961, como já afirmado, não foi a única. Em 22 de janeiro de 1962,

[...] Ministros das Relações Exteriores dos Estados-membros da Organização dos Estados Americanos (OEA) reuniram-se sob os auspícios do Tratado Interamericano de Assistência Recíproca (Tiar) para considerar “as ameaças à paz e à independência política dos Estados Americanos”. (...) Após dez dias de discussões, em 31 de janeiro, Cuba foi suspensa da Junta Interamericana de Defesa e da OEA, sendo que esta última decisão não contou com votos favoráveis dos maiores Estados latino-americanos. (FRANCHINI NETO, 2005, p. 2).

Assim, como revés dessas decisões, houve a exclusão do país cubano, que fora desamparado economicamente no período posterior à sua revolução, usando como resposta a sua aproximação ao bloco socialista, representado pela União das Repúblicas Socialistas Soviéticas (URSS), rival da maior potência representante do capitalismo, os Estados Unidos.

No Brasil, pode ser comprovado o acirramento das contradições manifestas por movimentos sociais populares, entre os quais as Ligas Camponesas, que explicavam a intensidade das reações norte-americanas, atentando-se para o comício realizado no Rio de Janeiro, em 13 de março de 1964. Durante esse comício, o presidente João Goulart, discursando para um público de 150 mil pessoas, comprometeu-se a implementar as mudanças conhecidas como "reformas de base". Tais reformas, as quais se confrontam com a expressão que aparece no discurso de Lincoln Gordon, podem ser assim compreendidas: a reforma agrária, a substituição das importações e o controle sobre a remessa de lucros de empresas estrangeiras que atuavam no Brasil. A orientação nacional-reformista adotada pelo presidente João Goulart desencadeou a oposição dos setores dominantes do país, de modo geral, grandes proprietários de terras, largos segmentos das classes médias e dos oficiais militares, além de setores conservadores da igreja católica. Como já registrava Julião (s/d, p. 83) sobre a questão da terra, no texto que escreveu para deixar à filha quando ainda preso durante a ditadura militar: "O latifúndio permanece assim, como um dente podre contaminando o corpo de uma Nação (...). Quando se propõe uma solução política para extingui-lo, surge a solução técnica. A primeira vê o homem. A segunda, a terra. Mas a terra deve servir ao homem".

Mais uma vez comprova-se, nas políticas destinadas à educação agrícola e à reforma agrária, formuladas pelos EUA, como, em contraposição a essas políticas, o compromisso assumido pelo presidente João Goulart com as reformas de base, entre estas a reforma agrária, que a terra está no centro das disputas. Portanto, é também a terra que está no bojo das 
reformas que vinculam a atual educação - do campo - ao trabalho e à propriedade da terra, conforme proposto no título do artigo. Assim, a propriedade da terra está no centro das disputas que atravessam a relação entre educação rural e reforma agrária. De um lado, estão as políticas formuladas pelos EUA e, de outro, está o compromisso do presidente João Goulart com as reformas de base, em que a reforma agrária não está dissociada da educação agrícola. Transferindo para o contexto atual, é também a terra que está no bojo das questões que vinculam a educação do campo ao trabalho agrícola e à luta pela reforma agrária, conforme o objetivo que orienta a análise feita neste artigo.

Retomando a discussão trazida até aqui, segundo Arapiraca (1982), a iniciativa de angariar parceiros entre os países periféricos da América Latina para definir uma política econômica, na ótica do capitalismo internacional para as Américas, lideradas pelos EUA, aconteceu na reunião de Punta del Este, em 1961. Mas somente em 1964, com o golpe militar, é que foram criadas as condições objetivas para que o Brasil assumisse um compromisso efetivo como parceiro. Porém, no âmbito da educação, o autor destaca a importância da Conferência que ocorreu no Chile, em 1962, quando o Sistema Interamericano acolhe "os acenos de parceria na expansão do capitalismo internacional e resolve assumir as recomendações do Plano Decenal da Aliança para o Progresso, expressos na Carta de Punta del Este em 1961" (ARAPIRACA, 1982, p. 174).

0 Brasil esteve presente e assinou, junto com outros países, os documentos de compromisso na Conferência de Punta del Este em 1961, no caso do Plano Decenal do Desenvolvimento da Aliança para o Progresso. Através dos acordos assinados nas duas conferências - a de 1961 em Punta del Este e a de 1962 em Santiago -, os representantes brasileiros assumiam compromisso de desenvolver um projeto educativo articulado ao desenvolvimento econômico, financiado pela USAID e pelo Banco Mundial. Entretanto, o dito compromisso só veio a efetivar-se com a derrubada do presidente brasileiro, João Goulart, substituído pela ditadura militar, que assume 0 poder em $1^{\circ}$ de abril de 1964 - coincidentemente, o dia da mentira na cultura popular. Inicia-se, a partir daí, uma severa perseguição a todos os que contestassem as bases dos acordos entre Brasil e Estados Unidos. A Aliança para o Progresso interferiu profundamente nas políticas adotadas pela ditadura militar, sendo que as pregações sobre "ordem e progresso", "segurança e desenvolvimento" marcaram principalmente, além dos planos econômicos e educacionais, o Plano de Segurança Nacional (ROCHA, 2005). Estudiosos das políticas que foram impostas pelos acordos entre Brasil e Estados Unidos voltadas à educação rural nas suas diferentes modalidades, Calazans, Castro, Silva (1981) registram suas críticas àqueles acordos. No texto analisado, os autores focalizam duas entidades, cuja atuação denota a transposição de projetos de outras realidades, uma vez que seus objetivos não refletem as necessidades do camponês brasileiro. A primeira é a Campanha Nacional de Educação Rural (CNER), inspirada em experiências efetuadas no México e nos Estados Unidos, com o apoio da Organização das Nações Unidas para a Educação, a Ciência e a Cultura (UNESCO).

A proposta da CNER era a de associar reformas na estrutura agrária à educação fundamental, de modo a promover uma recuperação integral das populações rurais. Subordinada ao MEC, a CNER se fazia presente na maior parte dos estados brasileiros, atuando através de centros de treinamento e de aperfeiçoamento, missões rurais, semanas educativas, cursos, conferências e campanhas educacionais. A outra entidade era a Associação Brasileira de Assistência Técnica e Extensão Rural (ABCAR), cujo propósito era adaptar os programas à realidade brasileira, através das ações extensionistas, tendo como modelo as experiências realizadas nos Estados Unidos desde o século XVIII: "Tratava-se, pois, de uma experiência de dois séculos, amplamente testada no 'país amigo'. No caso, o teste de sua eficácia 
já fora feito fora do país" (CALAZANS; CASTRO; SILVA, 1981, p. 194, nota de rodapé 17). Em obra posterior, Calazans (1993) aprofunda seus estudos sobre a CNER. A finalidade da CNER, criada em 1955, era desenvolver a formação de técnicos agrícolas para que estes se tornassem responsáveis pela educação de base, sob a orientação das diretrizes da UNESCO, para desenvolver os seguintes objetivos:

a) investigar e pesquisar as condições econômicas, sociais e culturais da vida rural brasileira; b) preparar técnicos para atender as necessidades da educação de base; c) promover e estimular a cooperação das instituições e dos serviços educativos existentes no meio rural e que visem o bem comum; d) concorrer para a elevação dos níveis econômicos da população rural pela introdução, entre os rurícolas, de técnicas avançadas de organização e de trabalho; e) contribuir para o aperfeiçoamento dos padrões educativos, sanitários, assistenciais, cívicos e morais das populações do campo; f) oferecer, enfım, orientação técnica e auxílio financeiro a instituições públicas e privadas que, atuando no meio rural, estejam integradas aos objetivos e finalidades do seu plano. (CALAZANS, 1993, p. 22, nota 21).

Fonseca (1985) é outra autora que se detém sobre a análise da educação rural, no período de 1948 - 1968, com destaque para a Extensão Rural que, como veremos, inclui-se nos propósitos do Ensino Técnico Agrícola (ETA). Para ela, a extensão rural é um projeto educativo destinado a fortalecer as relações entre capital e trabalho no campo. Afirma que o trabalho extensionista contribuiu para a

[...] ampliação da divisão social e técnica do trabalho neste setor, que necessariamente levaria à expropriação do trabalho e do saber de uma maioria para que ficasse garantido o domínio e o lucro de uma minoria. (FONSECA, 1985, p. 183).
Com isso, confirma-se a tese de que tanto a educação quanto a extensão rural vieram para fortalecer as relações de subordinação e expropriação do trabalho ao capital investido na produção agrícola, sob o controle dos Estados Unidos. Calazans (1993) também partilha dessa visão expressa por Fonseca (1985) e por Mendonça (2010). Documenta, em suas pesquisas, a criação de instituições de assistência técnica e extensão rural, nos anos de 1950, sob a influência e com financiamentos de agências norte-americanas. Uma delas é a Associação Brasileira de Assistência Técnica e Extensão Rural (ABCAR), criada em 1956, com a finalidade de captar recursos técnicos e financeiros para desenvolver programas de extensão rural. Confirmando a análise feita por Fonseca (1985) a respeito do caráter pedagógico da Assistência Técnica e da Extensão Rural, voltadas aos interesses do capital multinacional, Calazans (1993, p. 24) registra, como principais patrocinadores da ABCAR:

Organizações de "cooperação técnica", ligadas diretamente ao governo dos EUA (IIAA, ICA, AID, Uson, Aliança para o Progresso etc.); corporações, associações e fundações privadas, ditas "filantrópicas", ligadas ao grande capital monopolista americano (AIA, Fundação Ford, Fundação Rockfeller, Fundação Kellogs, etc.); organismos internacionais permeáveis aos interesses dos dois grupos acima mencionados e a que eles dão legitimidade, cobertura e prestígio, que, como eles, são instrumentos em nosso país de expansão da economia de mercado, e vendem uma imagem romântica da extensão rural. (IICA, OEA, BID, FA0 e BIRD).

Como visto até aqui, o ETA tem a pretensão de dar um novo sentido à educação agrícola, ao invés de rural, associada ao modelo de "desenvolvimento" defınido pelas organizações de “cooperação" técnica norte-americana. Essa é uma questão que se impõe na época e que, por isso 
mesmo, assume um significado especial dentro da chamada política de "cooperação" estadunidense. Assim, desviando a prioridade que era dada às atividades propriamente escolares, as atenções se voltam à assistência técnica, às orientações sobre crédito rural, à formação de mão de obra e ao apoio às organizações comunitárias, educando as populações trabalhadoras rurais para o consumo da tecnologia importada dos EUA, entendida como a mais avançada, o que as tornaria dependentes de tal tecnologia. Com isso, multiplicam-se as agências, até porque essa modalidade de educação, voltada à extensão rural, era menos dispendiosa.

Mendonça (2010) analisa as principais campanhas focadas na educação rural desenvolvidas no período de 1945-61, no Brasil, com apoio de técnicos norte-americanos. Essas campanhas decorrem dos acordos citados entre o governo brasileiro e dos Estados Unidos. Conforme a autora, o ETA assumiu o papel de redefınir o ensino técnico-agrícola, o que já estava posto como necessidade desde o início de 1940, distanciando-se do significado de escola para adotar a forma de práticas de extensão rural. Os recursos para o ETA eram provenientes do chamado Ponto IV, lançado em 1949, na gestão do Presidente Harry Truman, constituindo-se como o primeiro programa de auxílio internacional, mas não militar. Seu objetivo era "contribuir para o avanço econômico dos paises subdesenvolvidos, através do financiamento a projetos específicos junto a áreas como a Extensão Rural e o Crédito Supervisionado" (MENDONÇA, 2010, p. 141, itálico do original). Com isso, poder-se-ia afirmar que os projetos desenvolvidos nas áreas de fomento à produção agropecuária, auxílio e conservação de recursos naturais expressavam uma dimensão pedagógica direcionada às comunidades rurais.

Todavia, apesar de todo o cerceamento e pressão dos múltiplos programas de educação rural, assistência técnica, financiamento, entre outros, os camponeses não se deixavam amarrar facilmente, o que explica o golpe da ditadura militar, que derrubou o presidente João Goulart.
Então, da análise das políticas determinadas pelas relações de dominação dos EUA sobre os países da América Latina, em particular sobre o Brasil, passarei à análise de ações desenvolvidas pelos agricultores com a colaboração e apoio de lideranças de trabalhadores rurais, militantes da igreja católica e educadores populares.

\section{Educação popular de camponeses na contramão do movimento do capital}

Não é possivel analisar a relação entre a reforma agrária, o trabalho agrícola e a educação rural nas ditas "políticas de cooperação", em que se oculta o movimento do capital, sem fazer referência às formas como os trabalhadores, suas lideranças e apoiadores revertiam o movimento de pressão que sobre eles exerciam as políticas assentadas sobre determinações norte-americanas. $\mathrm{Na}$ impossibilidade de abordar a totalidade das ações camponesas, em que se destacam as Ligas Camponesas e as ações que têm suas origens nos movimentos sociais populares, pelos limites próprios de um artigo, vou deter-me sobre o Movimento de Educação de Base (MEB). Esse é um organismo vinculado à Conferência Nacional dos Bispos do Brasil (CNBB), constituído como sociedade civil de direito privado e sem fins lucrativos, com sede e foro no Distrito Federal.

O MEB foi fundado em 21 de março de 1961. Fávero (2006), com longa experiência no MEB como educador popular, escreve que, além da contribuição que esse movimento conferiu às populações pobres, nas áreas rurais, também apresentava limites, os quais abriam espaço à crítica, principalmente quanto à ausência de um referencial teórico que pudesse sustentar as análises, que, por isso mesmo, tornavam-se parciais e fragmentadas. Essas deficiências poderiam ser explicadas pela formação cristã dos educadores populares, bem como pelos pressupostos da doutrina social da igreja, que orientava a análise da realidade. Entretanto, para Fávero (2006, p. 268), a deficiência maior 
da educação popular feita pelo MEB, ou o seu limite, era acreditar "que o educativo teria força suficiente para mobilizar as populações rurais, a fim de que estas operassem transformações na estrutura econômico-social, desde que fosse encontrado um norte político adequado".

Do mesmo modo, o autor reflete que, tendo em conta a complexidade do problema que atingia as populações rurais no Brasil, nos anos de 1960, talvez fosse necessário relativizar essa análise para reconhecer a importância da ação educativa do MEB através dos programas radiofônicos. Isso porque, em toda a história da formação social brasileira, as populações camponesas foram utilizadas como "massa de manobra", até mesmo durante o início do período considerado populista (1945-1964), para atender aos interesses políticos, principalmente dos setores oligárquicos. Para Fávero (2006), nas áreas onde os conflitos em torno do trabalho e da propriedade da terra eram mais intensos, a ação pedagógica do MEB oferecia uma contribuição fundamental. Isso porque

Criticava a realidade e negava que a conjuntura dos países subdesenvolvidos, em particular, e a estrutura capitalista, em geral, pudesse vir a possibilitar a criação de um mundo para o homem, para todos os homens. (FÁVERO, 2006, p. 271).

Sobre a educação rural, implícita nas ações de educação popular do MEB, o pesquisador Osmar Fávero, que participou das atividades pedagógicas desse movimento na região nordeste brasileira, assim se pronuncia:

Mas no começo dos anos 50 por influência da OEA (Organização dos Estados Americanos) ou coisa assim é criada... É praticamente desdobrada a Campanha de Alfabetização desdobrada em Educação Rural. Essa proposta da UNESCO está na origem, está na origem tanto da Campanha de Alfabetização quanto da Campanha de Educação Rural. A Educação Rural preferiu trocar a educação de base por educação no campo. (...) Os bispos estavam preocupados, nesse momento, esses bispos progressistas, que não são tão revolucionários assim, só eram progressistas... Eles estavam preocupados com a entrada do comunismo no campo. Tinha até acontecido um grande congresso do PC [PCB - Partido Comunista Brasileiro] envolvendo lideranças rurais. Os comunistas basicamente já estavam no campo desde 1947, quando eles caem na ilegalidade. (FÁVERO, 2011) ${ }^{7}$.

0 depoimento desse pesquisador mostra que o MEB destinava-se prioritariamente às populações rurais. Esse é um movimento projetado e supervisionado por bispos e sacerdotes católicos e desenvolvido por agentes que defendiam a fé católica, assumindo essa religiosidade um caráter progressista, como o próprio pesquisador reconhece. Porém, ocultos pelos nobres objetivos das campanhas de alfabetização e da educação rural, estavam tanto o controle por parte de agências norte-americanas sobre o movimento das populações rurais quanto, por parte da igreja, o medo do comunismo, que se alastrava pelo campo com o discurso da reforma agrária.

Outro pesquisador que analisa a educação popular desenvolvida através do MEB é Wanderley (1984). Concordando com Fávero (2006), ele destaca como um grave problema o entendimento teórico que sustenta aquele movimento, no que se refere à conscientização como proposta da educação popular. Isso porque a teoria aponta a consciência de classe identificada com o movimento operário, tratando-se, então, de uma consciência operária. No MEB, entretanto, a população, sujeito da educação popular, em sua maioria era de camponeses. Estes, porém, pelo menos nos teóricos marxistas, cujas leituras predominavam no período estudado e fundamentavam as ações

7- Entrevista com o Prof. Dr. Osmar Fávero, que detém uma experiência histórica no MEB e uma produção na área da educação popular, na sua residência, na Rua Paulo César de Andrade, n. 70, apto. 203, Bairro de Laranjeiras, Rio de Janeiro. Data: 1\%/08/2011, das 9:50 h às 11:10 h. 
do PCB, deveriam integrar-se ao movimento operário, e ficar sob o comando deste, que se encontrava mais avançado na luta e na compreensão teórico-metodológica de como superar o capitalismo. Para o PCB, a demanda por reforma agrária, de acordo com Medeiros (2009) e concordando com Wanderley (1984), na obra citada, não foi definida estritamente a partir dos conflitos no campo. Isso porque um dos traços da linha política do partido era sobre o significado do latifúndio e da luta contra ele como um dos passos necessários de um conjunto de transformações pelas quais o país deveria passar no processo de uma revolução democrático-burguesa. Sob essa ótica, a reforma agrária era entendida como a eliminação dos latifundiários enquanto classe, procedendo-se à divisão das terras entre os que nela quisessem trabalhar. Mas, para o PCB, essa revolução seria liderada pelo movimento operário, ficando os camponeses na retaguarda, o que não confere com a história das revoluções onde elas aconteceram e que têm na sua base os movimentos camponeses, inclusive em Cuba (RIBEIR0, 2013).

É preciso lembrar, ainda, que a revolução cubana teve fortes repercussões na América Latina e no Brasil, quer sendo percebida como um exemplo a ser seguido por significativas lideranças do campo (Francisco Julião, das Ligas Camponesas, por exemplo) quer, no polo oposto, no sentido de alertar os setores dominantes sobre os possíveis riscos da permanência das formas de exploração e da miséria existentes. Um dos resultados políticos desse processo foi a constituição da Aliança para o Progresso, por iniciativa do governo dos Estados Unidos, conforme vimos anteriormente. Esse governo, através de seus embaixadores e técnicos, encorajava os governos latino-americanos a realizarem programas preventivos de reforma agrária que eliminassem a concentração fundiária e criassem condições para formar-se uma classe média rural.

Começa, então, a ficar mais clara a existência de uma disputa entre projetos econômi- co-políticos contraditórios de organização da sociedade. Tal disputa tem como foco a propriedade da terra, um meio de produção que está na natureza e ao qual se vincula o trabalho do camponês. Por isso, a reforma agrária relacionada ao trabalho agrícola e à educação rural está no centro do conflito em que se confrontam concepções antagônicas de sociedade, trabalho e educação.

Educação rural e ensino agrícola eram definidos pelos acordos estabelecidos entre 0 governo norte-americano e o governo brasileiro, com a justificativa de libertar do atraso o homem rural através da escola. Focalizavam principalmente a alfabetização. Isso se explica numa conjuntura marcada pelo final da II Guerra Mundial e pela adoção de uma política identificada como Guerra Fria, pelos EUA, e, no Brasil, pelo propósito de conter o avanço do comunismo na área rural.

Todavia, a reação à educação popular voltada à conscientização através do MEB não se fez esperar. Tendo sua origem em Recife, a Cruzada da Ação Básica Cristã $(\mathrm{ABC})$ pode ser vista como um movimento representativo de reação às experiências anteriores de educação popular. Como Paiva (1983) observa, suas diferenças não estavam apenas na visão política em confronto com a que se fazia presente na ação educativa do MEB e no que Moacyr de Góes (1986, p. 21) identifica como metodologia do sistema Paulo Freire. Essas diferenças transpareciam também nos objetivos, na metodologia e na visão a respeito do fenômeno educativo. Contrapondose ao material utilizado pelo MEB e pelas experiências de Paulo Freire e Moacir de Góes (1986), os materiais didáticos da Cruzada ABC difundiam a importância da escola para 0 fortalecimento da vida familiar, enfatizavam a necessidade da fé, do espírito religioso e da frequência à igreja, conforme escreve Arapiraca (1982). Além disso, também dedicavam espaço para divulgar a necessidade de lazer, de uma alimentação saudável e do dever de pagar os impostos, reforçando, nas suas instruções, além 
de outros temas, o da importância das Forças Armadas para "a manutenção da paz e da ordem interna" (PAIVA, 1983, p. 280). Embora bastante criticada, após o golpe militar de 1964, a Cruzada ABC impôs-se dentro de um contexto de autoritarismo que acabou por promover o esvaziamento da proposta do MEB.

Mas é necessário penetrar mais fundo na política interessada dos Estados Unidos em relação à América Latina. Desde cursos, com material em inglês, como o que foi promovido pelo INEP', até a presença de técnicos norte-americanos e o convite para professores universitários efetuarem uma formação em universidades estadunidenses, para depois assumirem postos de poder nos organismos destinados a aplicar as decisões, tudo estava sob o rígido controle dos Estados Unidos. 0 mais surpreendente, ainda, é que a maior parte do material utilizado para subsidiar o curso era em língua inglesa, com alguns textos em francês (CALAZANS, 1993). Isso comprova o distanciamento entre a realidade dos alunos brasileiros e das escolas rurais e a formação oferecida aos professores que iriam atuar nessas escolas, o que desvela os interesses contidos nessa pretensa formação. Maurício Tragtenberg faz uma análise sobre a relação entre saber e poder, apontando que a agricultura e o planejamento familiar constituíam áreas de interesse vital para as classes dominantes norte-americanas. Afirma que o interesse dos EUA pela

[...] formação de pessoal especializado deu-se após a desastrosa viagem de Nixon à América Latina em 1958 e a eclosão da revolução cubana. Os programas de estudo sobre a América Latina, que em 1958 chegavam a sessenta, em 1965 atingem 310. (TRAGTENBERG, 2004, p. 33).

Uma abordagem histórica da educação rural permite captar um movimento contraditório;

8 - Sobre isso, ver: relatório do curso promovido pelo INEP, em 1949, a cargo do Prof. Robert King Hall, da Columbia University, NY: Problemas de educação rural: a nova escola primária brasileira. Rio de Janeiro: Instituto Nacional de Estudos Pedagógicos, 1950. (Boletim, n. 47) de um lado, observa-se que, nos anos de 1930/40, há um incentivo à permanência dos agricultores no campo; e, de outro, nos anos de 1950/60, um estímulo para que os agricultores busquem direitos sociais e empregos nas cidades. 0 primeiro coincide com a crise econômica do período entre guerras e da Segunda Guerra Mundial. Nessa fase, os países formulam políticas públicas de controle dos conflitos sociais "como tentativa de resposta à 'questão social', provocada pela inchação das cidades e incapacidade de absorção de toda a mão de obra disponível pelo mercado de trabalho urbano" (CALAZANS, 1993, p. 24). Já no segundo, "esta questão social" não conta, pois as exigências de mão de obra, decorrentes dos processos de industrialização que se intensifıcam, irão promover um movimento migratório em busca de empregos e de escolas nas áreas urbanas.

Seria essa busca da educação do campo associada à terra de trabalho e, portanto, à reforma agrária, um acontecimento novo, próprio do final do século 20 e primeira década do século 21 , ou teria ela raízes mais profundas a serem buscadas na história?

Da busca das raízes da educação do campo na história da educação rural, conforme proposto na questão que orienta a análise neste artigo, emergem algumas reflexões acerca das possíveis conexões entre reforma agrária, trabalho agrícola e educação do campo, que envolvem o confronto de interesses, os quais podem significar enormes desafios a ser enfrentados por essa educação do campo.

\section{Cercas enormes colocam-se diante da educação do campo}

Uma busca na história dos interesses e, decorrentes destes, dos conflitos que estão na base da educação rural indissociavelmente vinculada à terra e, portanto, à reforma agrária, permite compreender as enormes cercas que a educação do campo precisa transpor para se concretizar e mesmo se consolidar. Isso porque essa educação, projetada pelo Movimento Camponês, também é atravessada por interesses 
contraditórios e, portanto, em conflito, apesar da diferença entre as formas de organização e expressão que assumem as forças do trabalho camponês e as forças do capital que atualmente se constituem como agronegócio. Assim, à guisa de conclusão e tomando como referência a análise histórica anteriormente feita, seleciono algumas questões que parecem fundamentais como contribuição ao avanço dessa educação do campo. Dos inúmeros desafios que enfrenta hoje a educação do campo e cujas raízes podem ainda estar fincadas no que era concebido e praticado como educação rural, destaco três: a) a escola do campo em relação à escola rural; b) a relação entre o trabalho camponês e a educação escolar; c) a reforma agrária como motor principal dos conflitos entre os grandes proprietários e os camponeses, considerando que a terra é um meio de produção original pelo fato de não ter sido obra do trabalho humano.

Quanto ao primeiro desafio, a população do campo diminuiu consideravelmente em relação ao período estudado. Porém, a escola do campo, em muitos casos, não difere da escola rural onde é transmitida uma cultura urbana, na pressuposição, ainda, de que esta significa um instrumento para superar o atraso do modo de vida camponês e propiciar, além da civilização, o desenvolvimento econômico-social. Mas estes - desenvolvimento e civilização não passam de meras abstrações, como mostram os autores que contribuíram para a análise histórica, entre os quais Silva (1994, p. 179181), que denuncia "a escalada da violência no campo", o "aumento da concentração fundiária e da pobreza rural" e a "inércia governamental”. Essa caracterização confırma-se quando se observam: as estruturas precárias em que funcionam as escolas; o despreparo dos professores porque, nos cursos que frequentaram, não foram incluídos conhecimentos relacionados à vida e ao trabalho no/do campo; e, por fim, as condições em que se faz o transporte das crianças para frequentar uma escola-polo, situada na sede do município, porque a prefeitura optou pelo processo de nucleação das escolas. Assim, a escola, pelos conteúdos que transmite, pelas condições em que funciona e pelo despreparo dos professores, pode ser uma via do abandono do campo por parte dos filhos e/ou das famílias. Com isso, a reforma agrária deixa de ser uma preocupação do capital tanto pelo fato de o comunismo não representar mais uma ameaça quanto porque a extensão da propriedade não entra em conflito com a produção agropecuária voltada à exportação; antes se sustenta sobre ela (SILVA, 1994, p. 142).

0 segundo desafio refere-se à relação indissociável entre o aprendizado e/ou a experiência no/do trabalho agrícola e a educação escolar. Como vimos, mesmo procurando estender conhecimentos relacionados às técnicas agrícolas, a extensão rural não chega a promover a relação trabalho-educação que sustenta a educação do campo, conquistada pelo MC (MORISSAWA, 2001; RIBEIRO, 2013). Não se aprende a ser agricultor nos bancos escolares, até porque, como observam os historiadores consultados, o currículo da escola rural, ainda existente na maior parte dos estados, não se diferencia daquele que orienta a escolarização das crianças nas áreas urbanas. A luta dos movimentos sociais populares, organizados no Movimento Camponês, pela educação do campo, inclui também a exigência de uma escola articulada ao trabalho camponês. Porém, a modalidade de escola oferecida às populações camponesas, não apenas pelo seu currículo, condições de funcionamento, professores, mas principalmente pela formulação do ano letivo dissociado das atividades produtivas, é uma porta de saída ou de abandono da escola e/ ou do campo. Com isso, ou seja, com a quebra do vínculo entre a escola e o trabalho na agricultura, na pesca, na pecuária ou na coleta, são criadas as condições e as justificativas para o abandono da terra e, nesse caso, deixa-se de lutar e de pensar em reforma agrária.

Por fim, a questão da terra - terceiro desafio -, presente no documento Estatuto da Terra - Lei $\mathrm{n}^{\circ} 4.504$ de 30 de novembro de 1964, produzido pela ditadura militar e 
identificado como a primeira lei de reforma agrária no Brasil (STÉDILLE, 2005, p. 119-156), bem como a função social da terra defınida pela Constituição Federal de 1988, permanecem apenas como registros documentais que não encontram forças nem apoio para se tornar uma conquista dos trabalhadores do campo e suas famílias. E isso não é de admirar quando sabemos que, em 1991, o Presidente Carlos Salinas, do México, propôs uma emenda à Constituição resultante da Revolução Mexicana, que possibilitou a divisão das terras comunais, os ejidos, em pequenas propriedades privadas, colocando um fim à distribuição de terras (TANAKA, 2004, p. 121). E, do mesmo modo, na China atual, um governo reformista planeja "liberar a propriedade privada no meio rural e aumentar os financiamentos à agricultura" (A NOVA..., 2013, p. 66). Assim, a perda do vínculo com a terra pela impossibilidade de uma reforma agrária, como a história vem mostrando, poderá ser um enorme muro de concreto a ser transposto pela educação do campo.

A questão da reforma agrária, no Brasil, como barreira ao avanço da educação do campo, é muito mais complexa do que à primeira vista pode parecer. Trago algumas contribuições de autores presentes na obra $A$ questão agrária hoje, organizada por João Pedro Stédille (1994). No Brasil, a agricultura dispõe das condições institucionais próprias do desenvolvimento capitalista que se impõe sobre a formação social brasileira, favorecendo o movimento de acumulação de capital, com o apoio do Estado: "Por isso mesmo, nenhum setor da burguesia tem interesse ponderável na reforma agrária" (GORENDER, 1994, p. 35, itálico do original). Embora defenda a necessidade e a possibilidade de uma reforma agrária camponesa-popular, Gorender (1994, p. 41) afirma ainda que:

0 desenvolvimento do capitalismo na agropecuária brasileira já se realiza por uma via que dispensa a reforma agrária e constitui mera racionalização utópica conceber a reforma agrária para eliminar formas arcaicas de relações de produção e "aperfeiçoar" o capitalismo brasileiro a fim de torná-lo compatível com a democracia.

No Brasil, para esse mesmo autor, há duas vias de desenvolvimento agrário que se confrontam: a via latifundiária associada ao agronegócio e a via da pequena exploração agrícola, à qual se pode associar a educação do campo, que enfrenta enormes dificuldades para manter-se e ampliar-se atendendo às necessidades das populações camponesas. E, ainda, para Sandroni (1994), a realização de uma reforma agrária, de fato, supera em muito a mera distribuição de terras aos agricultores sem terra, uma vez que interfere, de forma mais ampla, na economia e na política, podendo considerar-se como um processo social bastante profundo, que encontra, por isso, tantas barreiras para concretizar-se.

Em tempos de crise estrutural do capital, a partir de setembro de 2008, quando se rompe a bolha especulativa das bolsas de valores e dos bancos e, antecedendo essa crise, a aplicação de um neoliberalismo que estimula a competição entre os indivíduos e controla as políticas de Estado, parece não haver condições para uma luta pela reforma agrária. Além disso, a opção econômica do Brasil pelo agronegócio, que tem na terra, e em particular no latifúndio, a base para concretizar-se, empurra a reforma agrária, que fica cada vez mais distante daqueles que nessa terra trabalham. Assim, escola do campo, trabalho agrícola e terra como meio de produção das famílias dos agricultores se tornam cada vez mais difíceis de articular numa unidade a serviço daqueles que vivem do seu trabalho no/do campo. Com isso, tem-se os desafios - ou as cercas - para transpor rumo a articular a educação do campo ao trabalho camponês e à terra de trabalho. Mas cabe ao MC avançar ou se curvar à potência desse movimento do capital. 


\section{Referências}

A NOVA RENOVAÇÃO: The economist: a China planeja liberar a propriedade privada no meio rural e aumentar os financiamentos à agricultura. Carta Capital, São Paulo, v. 19, n. 774, p. 66-69, 13 nov. 2013.

ARAPIRACA, José Oliveira. A USAID e a educação brasileira. São Paulo: Cortez: Editores Associados, 1982.

BARBOSA, Guilherme Ubaldo. Entre o dito e o feito: as contradições da Aliança para o Progresso, 2008. 123 p. Dissertação (Mestrado em História Social) - Universidade de Brasília, Brasília, DF, 2008.

BARREIRO, Iraíde Marques de Freitas. Política de educação no campo (1952-1963). São Paulo: Cultura Acadêmica: UNESP, 2010.

BRASIL. Estatuto da terra - Lei nº 4.504 de 30 de novembro de 1964.

BRASIL. Decreto n 30.544, de 14 de fevereiro de 1952. Câmara dos Deputados. Promulga a Carta da Organização dos Estados Americanos, firmada em Bogotá, a 30 de abril de 1948. Disponível em: <www2.camara.leg.br/.../decreto-30544-14-fevereiro1952-340000-publi... >. Acesso em: 17 set. 2013.

CALAZANS, Maria Julieta Costa. Para compreender a educação do estado no meio rural: traços de uma trajetória. In: THERRIEN, Jacques; DAMASCENO, Maria Nobre. Educação e escola no campo. Campinas: Papirus, 1993. p. 15-51.

CALAZANS, Maria Julieta Costa (Coord.). Caracterização de programas de educação rural no Brasil: algumas experiências das três últimas décadas. Rio de Janeiro: IESAE/FGV, 1981. 85 p. $1^{\circ}$ relatório parcial.

CALAZANS, Maria Julieta Costa (Coord.). Estudo retrospectivo da educação rural no Brasil. Rio de Janeiro: IESAE/FGV, 1979. 192 p. Documento datilografado.

CALAZANS, Maria Julieta Costa; CASTRO, Luiz F. Meira; SILVA, Hélio R. Santos. Questões e contradições da educação rural no Brasil. In: WERTHEIN, Jorge; BORDENAVE, Juan Díaz. Educação rural no terceiro mundo. Rio de Janeiro: Paz e Terra, 1981. p. 161-223.

CARDOSO, Maria Angélica; JACOMELI, Mara Regina Martins. Estado da arte acerca das escolas multisseriadas. Revista HISTEDBR On-Line, Campinas, número especial, p. 174-193, mai., 2010. Disponível em: < http://www.fe.unicamp.br/revistas/ged/histedbr/ article/view/3606/3139>. Acesso em: ago. 2013.

CUNHA, Luiz Antônio. Educação e desenvolvimento social no Brasil. 7. ed. Rio de Janeiro: Francisco Alves, 1980.

FÁVERO, Osmar. Uma pedagogia da participação popular: análise da prática educativa do MEB (1961 - 1966). Campinas: Autores Associados, 2006. p. 263-272.

FONSECA, Maria Teresa Lousada. Extensão rural no Brasil: um projeto para o capital. São Paulo: Loyola, 1985.

FRANCHINI NETO, Hélio. A política externa independente em ação: a Conferência de Punta del Este de 1962. Revista Brasileira de Política Internacional, Brasília, DF, v. 48, n. 2, p. 129-151, jul./dez. 2005.

GÓES, Moacir de. Voz ativa. In: CUNHA, Luiz Antônio; GÓES, Moacyr de. 0 golpe na educação. 3. ed. Rio de Janeiro: Zahar, 1986. p. 7-34.

GORENDER, Jacob. Gênese e desenvolvimento do capitalismo no campo brasileiro. In: STEDILLE, João Pedro. (Org.). A questão agrária hoje. 2. ed. Porto Alegre: Editora da Universidade Federal do Rio Grande do Sul, 1994. p. 15-44.

GRAMSCI, Antonio. Cadernos do cárcere: os intelectuais. 0 princípio educativo. Jornalismo. 2. ed. Rio de Janeiro: Civilização Brasileira, 2001. v. 2.

JULIÃO, Francisco. Até quarta, Isabela! Rio de Janeiro: Civilização Brasileira, [19--]. Carta escrita no cárcere. Exemplar n. 4489. 
LIRA, Débora Amélia; MELO, Amilka Dayane Dias. Educação brasileira no meio rural: recortes no tempo e no espaço. In: SEMINÁRIO DE PESQUISAA CCSA, 16. Natal, 2010. Universidade e formação profissional e atuação no mundo contemporâneo. Natal: UFRN, 2010. $18 p$.

MAIA, Eni Marisa. Educação rural no Brasil: o que mudou em 60 anos? Em Aberto, Brasília, DF, v. 1, n. 9, p. 27-33, set. 1982.

MARINI, Ruy Mauro. Dialética da dependência. Petrópolis: Vozes; Buenos Aires: CLACSO, 2000.

MARX, Karl. 0 capital: crítica da economia política. São Paulo: Difel, 1982. 2 v. Livro primeiro: 0 processo de produção do capital. MARX, Karl; ENGELS, Friedrich. Textos sobre educação e ensino. São Paulo: Moraes, 1983.

MEDEIROS, Leonilde Servolo de. A questão agrária. Cadernos do Desenvolvimento, São Paulo, v. 4, p. 71-76, 2009.

MENDONÇA, Sonia Regina de. Conflitos intraestatais e políticas de educação agrícola. Tempos Históricos, Marechal Cândido Rondon, Edunioeste, v. 10, p. 243-266, 2007.

MENDONÇA, Sonia Regina de. Ensino agrícola e influência norte-americana no Brasil (1945-1961). Tempo: Revista do Departamento de História da UFF, Rio de Janeiro, v. 15, n. 29, p. 139-165, 2010.

MOTA, André. Higienizando a raça pelas mãos da educação ruralista: 0 caso de Grupo Escolar Rural do Butantan em 1930. Interface Comunicação Saúde Educação, Botucatu, v. 14, n. 32, p. 9-22, jan./mar. 2010.

MORISSAWA, Mitsue. A história da luta pela terra e o MST. São Paulo: Expressão Popular, 2001.

NAGLE, Jorge. Educação e sociedade na Primeira República. 2. ed. Rio de Janeiro: DP\&A, 2001.

PASSOS, Juliana. Operação Aliança: entre a Operação Pan-Americana e a Aliança para o Progresso. In: SIMPÓSIO NACIONAL DE HISTÓRIA, 25., 2009, Fortaleza, 12 a 17 de jul. 2009. 9 p.

PAIVA, Vanilda Pereira. Educação popular e educação de adultos. 2. ed. São Paulo: Loyola, 1983.

PINTO, João Bosco. A educação de adultos e o desenvolvimento rural. In: WERTHEIN, Jorge; BORDENAVE, Juan Díaz. Educação rural no terceiro mundo: experiências e novas alternativas. Rio de Janeiro: Paz e Terra, 1981. p. 65-102.

PRADO, Adonia Antunes. Ruralismo pedagógico no Brasil do Estado Novo. Estudos Sociedade e Agricultura, Rio de Janeiro, n. 4, p. 5-27, jul. 1995. Disponível em: <http://bibliotecavirtual.clacso.org.ar/ar/libros/brasil/cpda/estudos/quatro/adonia4.htm>. Acesso em: 15 ago. 2013.

PRADO JÚNIOR, Caio. A questão agrária e a revolução brasileira - 1960. In: STEDILLE, João Pedro (Org.). A questão agrária no Brasil 1. 0 debate tradicional: 1500-1960. São Paulo: Expressão Popular, 2005. p. 79-87.

RIBEIRO, Marlene. Movimento camponês, trabalho, educação. Liberdade, autonomia, emancipação: princípios/fins da formação humana. 2. ed. São Paulo: Expressão Popular, 2013.

ROCHA, Dário do Carmo. A Carta de Punta del Este: as ideias positivistas nas reformas educacionais e no Plano de Segurança Nacional orquestradas na década de 60. In: SEMINÁRIO ESTADO E POLÍTICAS SOCIAIS NO BRASIL, 2., 2005, Cascavel, 13 a 15 de out. 2005.

SANDRONI, Paulo. A questão agrária e o socialismo: notas sobre problemas econômicos e políticos. In: STEDILLE, João Pedro (Org.). A questão agrária hoje. 2. ed. Porto Alegre: UFRGS, 1994. p. 152-164.

SILVA, José Gomes da. 0 desenvolvimento do capitalismo no campo brasileiro e a reforma agrária. In: STEDILLE, João Pedro (Org.). A questão agrária hoje. 2. ed. Porto Alegre: UFRGS, 1994. p. 165-190.

SILVA, José Graziano da. Viabilidade de uma reforma agrária em São Paulo. In: STEDILLE, João Pedro (Org.). A questão agrária hoje. 2. ed. Porto Alegre: UFRGS, 1994. p. 191-202. 
STEDILLE, João Pedro (Org.). A questão agrária no Brasil 3. Programas de reforma agrária: 1946-2003. São Paulo: Expressão Popular, 2005.

TANAKA, Laura Saldivar. A reforma agrária mexicana: do ejido à privatização. In: MARTINS, Mônica Dias (Org.). 0 Banco Mundial e a terra. São Paulo: Viramundo, 2004. p. 121-144.

TRAGTENBERG, Maurício. Sobre educação, política e sindicalismo. 3. ed. São Paulo: UNESP, 2004. p. 21-44.

VEIGA, José Eli da. Fundamentos do agrorreformismo. In: STEDILLE, João Pedro (Org.). A questão agrária hoje. 2. ed. Porto Alegre: UFRGS, 1994. p. 68-93.

WANDERLEY, Luiz Eduardo. Concepção de educação de base e as práticas educativas do MEB: politização. In: WANDERLEY, Luiz Eduardo. Educar para transformar: educação popular, igreja católica e política no movimento de educação de base. Petrópolis: Vozes, 1984. p. 97-222.

Recebido em: 26.08.2013

Aprovado em: 11.12.2013

Marlene Ribeiro é doutora em educação pela Universidade Federal do Rio Grande do Sul e professora titular da mesma universidade. 